\title{
Long-term exposure to outdoor and household air pollution and blood pressure in the Prospective Urban and Rural Epidemiological (PURE) study
}

\author{
Raphael E. Arku ${ }^{\text {a, b, *, Michael Brauer }}{ }^{\text {b }}$, Suad H. Ahmed ${ }^{\text {c }}$, Khalid F. AlHabib ${ }^{\text {d }}$,
} Álvaro Avezum ${ }^{\mathrm{e}}$, Jian Bo ${ }^{\mathrm{f}}$, Tarzia Choudhury ${ }^{\mathrm{g}}$, Antonio ML. Dans ${ }^{\mathrm{h}}$, Rajeev Gupta ${ }^{\mathrm{i}}$, Romaina Iqbal ${ }^{\mathrm{j}}$, Noorhassim Ismail ${ }^{\mathrm{k}}$, Roya Kelishadi ${ }^{l}$, Rasha Khatib ${ }^{\mathrm{m}}$, Teo Koon ${ }^{\mathrm{n}}$, Rajesh Kumar ${ }^{\circ}$, Fernando Lanas ${ }^{\mathrm{P}}$, Scott A. Lear ${ }^{\mathrm{q}}$, Li Wei ${ }^{\mathrm{f}}$, Patricio Lopez-Jaramillo ${ }^{\mathrm{r}}$, Viswanathan Mohan ${ }^{\mathrm{s}}$, Paul Poirier ${ }^{\mathrm{t}}$, Thandi Puoane ${ }^{\mathrm{u}}$, Sumathy Rangarajan ${ }^{\mathrm{n}}$, Annika Rosengren ${ }^{\mathrm{v}}$, Biju Soman ${ }^{\mathrm{w}}$, Ozge Telci Caklili ${ }^{\mathrm{x}}$, Shunyun Yang ${ }^{\mathrm{y}}$, Karen Yeates ${ }^{\mathrm{z}}$, Lu Yin ${ }^{\mathrm{f}}$, Khalid Yusoff ${ }^{\text {aa }}$, Tomasz Zatoński ${ }^{\mathrm{ab}}$, Salim Yusuf ${ }^{\mathrm{n}}$, Perry Hystad ${ }^{\mathrm{ac}}$

a Department of Environmental Health Sciences, School of Public Health and Health Sciences, University of Massachusetts, Amherst, MA, USA

b School of Population and Public Health. The University of British Columbia, Vancouver, BC, Canada

c Dubai Health Authority, United Arab Emirates

d College of Medicine, King Saud University, Saudi Arabia

e Dante Pazzanese Institute of Cardiology and University of Santo Amaro, São Paulo, Brazil

${ }^{\mathrm{f}}$ Fuwai Hospital, Peking Union Medical College \& Chinese Academy of Medical Sciences, Beijing, China

$\mathrm{g}$ Independent University, Bangladesh

h Philippine General Hospital, Manila, Philippines

${ }^{\mathrm{i}}$ Eternal Heart Care Centre and Research Institute, Jaipur, India

j Departments of Community Health Sciences and Medicine, The Aga Khan University, Karachi, Pakistan

${ }^{\mathrm{k}}$ Faculty of Medicine, University Kebangsaan, Kuala Lumpur, Malaysia

${ }^{1}$ Cardiovascular Research Institute, Isfahan University of Medical Sciences, Iran

${ }^{m}$ Advocate Research Institute, Advocate Health Care, Downers Grove, IL, USA

${ }^{n}$ Population Health Research Institute, Hamilton Health Sciences and McMaster University, Hamilton, ON, Canada

o School of Public Health, PGIMER, Chandigarh, India

${ }^{\mathrm{p}}$ Universidad de La Frontera, Temuco, Chile

q Simon Fraser University, Vancouver, Canada

${ }^{\mathrm{r}}$ Research Institute FOSCAL and Masira Institute, UDES, Bucaramanga, Colombia

${ }^{s}$ Madras Diabetes Research Foundation, Chennai, India

${ }^{\mathrm{t}}$ Université Laval and Institut universitaire de cardiologie et de pneumologie de Québec, Québec, Canada

u School of Public Health, University of the Western Cape, Bellville, South Africa

${ }^{v}$ University of Gothenburg and Sahlgrenska University Hospital Gothenburg, Sweden

${ }^{\mathrm{w}}$ Sree Chitra Tirunal Institute for Medical Sciences \& Technology, Trivandrum, Kerala, India

${ }^{x}$ Istanbul University, Faculty of Medicine, Department of Endocrinology and Metabolism, Turkey

${ }^{y}$ Center for Disease Control and Prevention, Yunnan, China

z Queen's University, Kingston, Ontario, Canada

aa UCSI University, Kuala Lumpur, Malaysia \& Universiti Teknologi MARA, Selayang, Malaysia

${ }^{\mathrm{ab}}$ Department of Otolaryngology Head and Neck Surgery, Medical University, Wrockaw, Poland

ac School of Biological and Population Health Sciences, College of Public Health and Human Sciences, Oregon State University, Corvallis, OR, USA

\section{A R T I C L E I N F O}

Article history:

Received 25 July 2019

Received in revised form

27 January 2020

\section{A B S T R A C T}

Exposure to air pollution has been linked to elevated blood pressure (BP) and hypertension, but most research has focused on short-term (hours, days, or months) exposures at relatively low concentrations. We examined the associations between long-term (3-year average) concentrations of outdoor $\mathrm{PM}_{2.5}$ and household air pollution (HAP) from cooking with solid fuels with BP and hypertension in the Prospective

\footnotetext{
* Corresponding author. School of Public Health and Health Sciences, University of Massachusetts, Amherst, MA, USA.

E-mail address: rarku@umass.edu (R.E. Arku).
} 
Accepted 14 February 2020

Available online 24 February 2020

\section{Keywords:}

Air pollution

Global health

Household

Hypertension

Blood pressure

Cardiovascular
Urban and Rural Epidemiology (PURE) study. Outdoor $\mathrm{PM}_{2.5}$ exposures were estimated at year of enrollment for 137,809 adults aged 35-70 years from 640 urban and rural communities in 21 countries using satellite and ground-based methods. Primary use of solid fuel for cooking was used as an indicator of HAP exposure, with analyses restricted to rural participants $(n=43,313)$ in 27 study centers in 10 countries. BP was measured following a standardized procedure and associations with air pollution examined with mixed-effect regression models, after adjustment for a comprehensive set of potential confounding factors. Baseline outdoor $\mathrm{PM}_{2.5}$ exposure ranged from 3 to $97 \mu \mathrm{g} / \mathrm{m}^{3}$ across study communities and was associated with an increased odds ratio (OR) of 1.04 (95\% CI: 1.01, 1.07) for hypertension, per $10 \mu \mathrm{g} / \mathrm{m}^{3}$ increase in concentration. This association demonstrated non-linearity and was strongest for the fourth $\left(\mathrm{PM}_{2.5}>62 \mu \mathrm{g} / \mathrm{m}^{3}\right)$ compared to the first $\left(\mathrm{PM}_{2.5}<14 \mu \mathrm{g} / \mathrm{m}^{3}\right)$ quartiles $(\mathrm{OR}=1.36$, 95\% CI: $1.10,1.69)$. Similar non-linear patterns were observed for systolic $\mathrm{BP}(\beta=2.15 \mathrm{mmHg}, 95 \%$ $\mathrm{CI}:-0.59,4.89)$ and diastolic $\mathrm{BP}(\beta=1.35,95 \% \mathrm{CI}:-0.20,2.89)$, while there was no overall increase in ORs across the full exposure distribution. Individuals who used solid fuels for cooking had lower BP measures compared to clean fuel users (e.g. $34 \%$ of solid fuels users compared to $42 \%$ of clean fuel users had hypertension), and even in fully adjusted models had slightly decreased odds of hypertension $(\mathrm{OR}=0.93$. 95\% CI: $0.88,0.99)$ and reductions in systolic $(-0.51 \mathrm{mmHg} ; 95 \% \mathrm{CI}:-0.99,-0.03)$ and diastolic $(-0.46 \mathrm{mmHg} ; 95 \% \mathrm{CI}:-0.75,-0.18) \mathrm{BP}$. In this large international multi-center study, chronic exposures to outdoor $\mathrm{PM}_{2.5}$ was associated with increased $\mathrm{BP}$ and hypertension while there were small inverse associations with HAP.

() 2020 Elsevier Ltd. All rights reserved.

\section{Introduction}

High blood pressure (BP) is a leading global risk factor for overall disease burden (Collaborators, 2018; Chow et al., 2013; Yusuf et al., 2014). Exposure to both outdoor (Brook et al., 2010; Pope et al., 2015; Chan et al., 2015; Fuks et al., 2011; Chuang et al., 2010; Newby et al., 2015; Zhang et al., 2018) and household air pollution (HAP) (McCracken et al., 2007; Baumgartner et al., 2011; McCracken et al., 2012; Arku et al., 2017) has been linked to elevated BP. However, studies of outdoor $\mathrm{PM}_{2.5}$ (particles below $2.5 \mu \mathrm{m}$ in aerodynamic diameter) and BP have focused on short-term exposures and been conducted mainly in high income countries (Brook et al., 2010; Newby et al., 2015; Shah et al., 2015; Du et al., 2016), while most studies of HAP and BP have included relatively small study populations and been restricted to specific communities or populations (McCracken et al., 2012; Arku et al., 2017).

The overall evidence regarding outdoor $\mathrm{PM}_{2.5}$ and $\mathrm{BP}$ is less established for chronic exposures (Brook et al., 2010; Chan et al., 2015; Fuks et al., 2011; Chuang et al., 2010; Newby et al., 2015; Zhang et al., 2018; Burnett et al., 2014), with very limited data from the developing regions of the world that bears some of the highest $\mathrm{PM}_{2.5}$-cardiovascular disease burden (Tzoulaki et al., 2016; Kwan et al., 2016). Only a few studies, mostly focused on specific communities or sub-populations, have demonstrated associations between HAP and increased BP (McCracken et al., 2012; Arku et al., 2017), and only one included populations from multiple regions of the world (Arku et al., 2017). In this and other HAP studies, the estimated effect size of HAP on BP and hypertension has been small or weak (McCracken et al., 2012; Arku et al., 2017).

To further understand the potential role of long-term exposure to outdoor $\mathrm{PM}_{2.5}$ and HAP on BP, we leveraged the Prospective Urban and Rural Epidemiological (PURE) study and examined outdoor $\mathrm{PM}_{2.5}$ for 137,809 adults aged 35-70 years from 640 urban and rural communities in 21 countries. We also examined HAP from solid fuel use for cooking in a subset of 43,313 individuals living in rural communities where more than $10 \%$ of participants used solid fuels. These cross-sectional analyses capture an extremely large range of outdoor $\mathrm{PM}_{2.5}$ exposures, various household cooking settings, and diverse individual and community characteristics, thus contributing important new information on the relationship between air pollution with BP and hypertension.

\section{Methods}

\subsection{Study design and population}

We included the original 141,471 PURE study participants recruited between 2001 (India) and 2014 (Saudi Arabia) from 640 urban and rural communities in 21 low-, middle-, and high-income countries. After excluding participants with incomplete systolic and diastolic BP measurements ( $3 \%)$, the final population used in this analysis involved 137,809 adults aged $35-70$ years (Table 1 ). PURE study countries were purposively selected to reflect varied income regions of the world, with more emphasis placed on low- and middle-income regions. Study "communities" in each country represented neighborhoods in urban areas and small villages in rural areas, but were not meant to be representative of the country. However, PURE was designed to achieve a representative sample of adults and households in each study community (Teo et al., 2009).

At study entry, a comprehensive set of individual-, household-, and community-level information was collected (see Teo et al. (2009) and Yusuf et al. (2014)). This included individual sociodemographic characteristics, lifestyle behaviors (e.g. smoking, physical activity and dietary profiles), medical history, anthropometric measures and BP. In addition, household data were collected on cooking methods as well as fuel types, which were used as a surrogate for HAP. Hamilton Health Sciences Research Ethics Board, Oregon State University Research Ethics Board, The University of British Columbia Behavioral Research Ethics Board (H14-02982), and the local ethics committees in the participating countries approved this study.

\subsection{BP measurement}

Sitting BP during the morning was measured at baseline by trained research assistants following a standardized procedure using Omron digital BP measuring devices (Omron HEM-757) (Chow et al., 2013; Yusuf et al., 2004). The measurements occurred for different amounts of time (days to months) in each study community depending on the number of participants and the size of the local field staff. Considering that BP readings could be influenced by subject's immediate activities and "white coat effect" (Ramli et al., 2008), subjects were asked not to smoke, ingest food 
Table 1

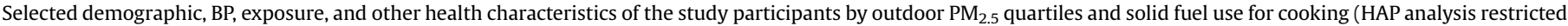
to rural communities).

\begin{tabular}{|c|c|c|c|c|c|c|c|c|}
\hline \multirow[t]{2}{*}{$\mathrm{PM}_{2.5}$ quartile $(\mu \mathrm{g} / \mathrm{m} 3)$} & \multirow{2}{*}{$\begin{array}{l}\text { Entire sample } \\
(\mathrm{n}=137,809)\end{array}$} & \multicolumn{4}{|l|}{ PM2.5 Analysis } & \multicolumn{3}{|l|}{ HAP Analysis } \\
\hline & & Q1 (2.6-14.0) & Q2 (14.0-25.4) & Q3 (25.4-62.0) & Q4 (62.0-97.0) & $\begin{array}{l}\text { Entire sample } \\
(\mathrm{n}=43,313)\end{array}$ & $\begin{array}{l}\text { Solid fuel } \\
(n=30,008)\end{array}$ & $\begin{array}{l}\text { Electricity/Gas } \\
(\mathrm{n}=13,305)\end{array}$ \\
\hline Systolic BP (mmHg) [ $\bar{x}(\mathrm{sd})]$ & $131.4(21.7)$ & $132.6(21.4)$ & $128.9(21.7)$ & $130.8(21.6)$ & $133(21.9)$ & $131.1(22.9)$ & $130.1(23.1)$ & $133.3(22.1)$ \\
\hline Diastolic BP (mmHg) $[\bar{x}(\mathrm{sd})]$ & $81.7(12.4)$ & $82.3(12.5)$ & $80(12.2)$ & $81.8(12.4)$ & $82.8(12.2)$ & $81.8(13.0)$ & $81.1(13.0)$ & $83.2(12.7)$ \\
\hline Age (years) $[\bar{x}(\mathrm{sd})]$ & $50.6(9.8)$ & $51.9(9.5)$ & $50(9.8)$ & $49.9(9.7)$ & $50.7(9.9)$ & $49.5(9.8)$ & $49.4(9.8)$ & $49.6(9.6)$ \\
\hline BMI $\left(\mathrm{Kg} / \mathrm{m}^{2}\right)[\bar{x}(\mathrm{sd})]$ & $25.9(5.2)$ & $27.2(5.5)$ & $25.8(5.8)$ & $25.6(4.9)$ & $24.8(4.2)$ & $23.8(4.5)$ & $23.2(4.3)$ & $25.2(4.6)$ \\
\hline \% Rural & 46.2 & 58.4 & 36.7 & 49.0 & 40.6 & & & \\
\hline \% Women & 58.0 & 58.2 & 58.2 & 58.1 & 57.0 & 42.4 & 57.6 & 57.8 \\
\hline$\%$ Dirty fuel ${ }^{a}$ & 28.7 & 14.0 & 28.5 & 38.2 & 33.1 & & & \\
\hline$\%$ Current smokers & 20.9 & 18.0 & 22.7 & 22.9 & 21.1 & 25.1 & 26.7 & 22.6 \\
\hline$\%$ Hypertension & 40.2 & 44.5 & 36.2 & 38.1 & 41.8 & 36.7 & 34.2 & 42.2 \\
\hline \% Diabetes & 8.0 & 6.9 & 11.1 & 7.0 & 7.2 & 4.7 & 3.8 & 6.7 \\
\hline \% Anti-hypertensive medication & 13.8 & 17.8 & 12.9 & 11.7 & 13.0 & 8.7 & 6.7 & 13.2 \\
\hline $\mathrm{PM}_{2.5}\left(\mu \mathrm{g} / \mathrm{m}^{3}\right)[\bar{x}(\mathrm{sd})]$ & $36.2(25.9)$ & $9.5(2.5)$ & $19.6(3.3)$ & $43.3(12.8)$ & $73.2(9.9)$ & $40.2(24.7)$ & $41.1(23.7)$ & $38.0(26.6)$ \\
\hline
\end{tabular}

a Solid fuel + kerosene.

or caffeine beverages, or exercise (including stair climbing) in the previous $30 \mathrm{~min}$ prior to the time of measurement. Also, just before the measurement, subjects were made to rest quietly for at least $5 \mathrm{~min}$. Two systolic and diastolic BP measurements in the right arm were taken about 1 min apart using the brachial artery. The mean of the two measurements was used for all analyses (Teo et al., 2009). We assumed that these home BP measurements were representative of the participants' average BP.

We assessed hypertension as an average systolic BP $\geq 140 \mathrm{~mm}$ $\mathrm{Hg}$ and average diastolic BP $\geq 90 \mathrm{~mm} \mathrm{Hg}$, or reported use of antihypertensive medication, which was defined as regular use of any or combination of angiotensin-converting enzyme inhibitors, diuretics, beta-blockers, angiotensin-receptor blockers, calciumchannel blockers, $\alpha$-blockers, and other BP lowering medications. We also assessed pulse pressure (PP = systolic-diastolic $\mathrm{BP})$ and mean arterial pressure (MAP $=\mathrm{PP} / 3+$ diastolic $\mathrm{BP}$ ) (Chan et al., 2015), to explore possible mechanisms through which exposures may affect BP. Individual BP records (continuous) and the hypertension status (yes vs. no) were analyzed separately.

\subsection{Community outdoor $P M_{2.5}$ exposure assessment}

$\mathrm{PM}_{2.5}$ concentrations were from a $1 \times 1 \mathrm{~km}$ global model created by van Donkelaar et al. (van Donkelaar et al., 2016). Briefly, the estimates were from a geographically weighted regression model using data from various satellite-, simulation-, and ground monitorbased sources. The raw satellite and ground monitor input data covered years 2001-2013 and valid model predictions were made for years 1999-2015, covering the study enrollment period (2001-2014). The model prediction of out-of-sample cross-validated $\mathrm{PM}_{2.5}$ concentrations from available ground monitors was $R^{2}=0.81$. We assigned annual $\mathrm{PM}_{2.5}$ concentrations (from $1 \times 1 \mathrm{~km}$ resolution) to the 640 PURE communities with each estimate representing a 3-year average centered on the year the community was enrolled in the study. For example, a community which was enrolled in 2011, would be assigned annual $\mathrm{PM}_{2.5}$ concentrations of the average of the 2010, 2011, and 2012 means. As all study subjects were established residents in the community prior to the study baseline (and had indicated their intention to remain into the foreseeable future), we assumed that the 3-year mean exposure centered on the enrollment year was reasonable estimates of their long-term $\mathrm{PM}_{2.5}$ exposures.

\subsection{Household air pollution assessment}

Questionnaires completed at study enrollment were used to collect information on household characteristics. We used records on households' primary cooking fuel type as an indicator of HAP exposure in terms of solid (coal, charcoal, wood, agriculture/crop products, shrub/grass and animal dung) vs. clean fuels (electricity and gas). This is a common proxy indicator for HAP exposure (Smith et al., 2014), and was our a-priori exposure measure for HAP.

\subsection{Statistical analyses}

Mixed-effect linear and logistic regression models were used to examine the association of community chronic average $\mathrm{PM}_{2.5}$ levels and HAP exposure with individual BP measurements and hypertension status (yes/no). We adjusted for numerous covariates selected a priori from existing literature on BP and air pollution. To accommodate the clustered nature of the PURE study design (i.e. individuals nested within communities nested within countries), and to capture unmeasured variables at such large geographic scales, we included a nested random effect for country and community or center as specified in the following models:

$$
\begin{aligned}
& B P=\beta_{0}+\beta_{\text {Outdoor PM2.5 }}+\beta X+b+\lambda+\varepsilon \\
& B P=\beta_{0}+\beta_{\text {Household cooking fuel }}+\beta X+b+\lambda+\varepsilon
\end{aligned}
$$

where $B P$ is the mean systolic BP, diastolic BP, PP, or MAP ( $\mathrm{mm} \mathrm{Hg}$ ); $X$ is a vector of individual-, household-, and community-level covariates; $b$ and $\lambda$ are country and community (equation $A$ ) or center (equation $B$ ) random intercepts; $\beta_{0}, \beta$ and $\gamma$ are regression coefficients. We did not include random effects for household to account for multiple subjects from the same household as our results remained identical with or without this factor. For the same reason, we did not include the year of community enrollment as a way to control for potential time trends in the PM data.

We assessed model sensitivity in both the outdoor (Equation A) and HAP models (Equation B). First, we specified a base model (Model 1) which included age (years), gender (male, female), and race/ethnicity; and then added progressively more groups of socioeconomic and clinical covariates in subsequent models. Model 2 included factors related to socioeconomic status, involving education (none, primary, secondary/high school/higher secondary, trade 
school, college/university, unknown), marital status (married, not married), and a household wealth index (based on household assets, and calculated separately for each country). The fully adjusted model (Model 3) further included cardiovascular disease (CVD) risk factors of smoking status (never smoked, former smoker, current smoker), alcohol use (never used, former user, current user), body mass index (BMI; $\mathrm{Kg} / \mathrm{m}^{2}$ ), alternative healthy eating index (a composite indicator for overall diet quality based on the dietary guidelines for Americans, computed for each household) (Guenther et al., 2008), as well as community-level factors comprising of temperature $\left({ }^{\circ} \mathrm{C}\right)$, geographical latitude (Cabrera et al., 2016), country income-level, and location of residence (urban, rural), in addition to the use of BP lowering medication (medication use, no medication use). All models included random intercepts for country and community or study center. Together, these models contained a vast amount of individual-, household-, and communitylevel covariates on participants from both rural and urban communities, and thus reduced the possibility of omitted variable bias or residual confounding.

Through stratified analyses for both the outdoor (Equation A) and HAP models (Equation B), we used the full model (Model 3) to explore potential differences in effect estimates by gender, urban/ rural residence (equation A/outdoor model only), hypertension status (equation A/outdoor model only), use of anti-hypertensive medication, body mass index (BMI, categorized as underweight, normal weight, overweight, and obese), smoking, alcohol use, age, and CVD and diabetes mellitus disease status. Additional analysis was conducted for participants who were free of CVD, diabetes mellitus, and did not take BP medication.

The HAP analysis was restricted to rural communities in study centers where $>10 \%$ of study participants used solid fuel for cooking. This was done to ensure a balanced sample, as most high- and upper-middle income countries contained in the outdoor analysis do not use solid fuel, and even in low-income countries the vast majority of solid fuel use by PURE participants was in the rural communities (93\%). Those who used kerosene $(1.2 \%)$ or other unclassified fuel types $(0.7 \%)$ for cooking were also excluded, leaving 43,313 rural participants who cooked primarily with either solid or clean fuels for this analysis.

We also conducted additional sensitivity analysis for HAP by pooling center-specific models using random-effects meta-analysis. This was done to explore the potential heterogeneity of HAP and BP results by region, since HAP exposure could vary by unmeasured household or community characteristics, fuel conditions/ types, cooking practices, customs, etc. Thus, the adjusted pooled effect estimates represent the weighted mean of the center-specific effect estimates, after assigning weights based on the inverse variance which included both within- and between-center variances.

We further explored the impact of joint exposures from both outdoor $\mathrm{PM}_{2.5}$ and HAP by examining the interaction between $\mathrm{PM}_{2.5}$ and HAP as well as by comparing the association for $\mathrm{PM}_{2.5}$ separately among clean versus dirty fuel users, using the fullyadjusted outdoor model (Model 3 in Equation A). We also compared HAP association among the lowest versus highest $\mathrm{PM}_{2.5}$ quartiles (Model 3 in Equation B).

We report the odds of having hypertension and changes in $\mathrm{BP}$ parameters for a $10 \mu \mathrm{g} / \mathrm{m}^{3}$ increase in $\mathrm{PM}_{2.5}$ to facilitate comparison with other studies. In contrast, HAP analyses compared estimates in individuals who cooked with solid fuel to clean fuel users. All analyses were implemented with the open-source statistical package $\mathrm{R}$ version 3.4.1 (R Project for Statistical Computing).

\section{Results}

The final population used in this analysis included 137,809 individuals from 97,708 households in 640 communities (342 urban and 298 rural) in 21 countries ( 4 high-income, 12 lower and upper middle-income, and 5 low-income) on five continents (Fig. 1A). About 2/3 of the participants were from lower middle- and lowincome countries. The mean age (standard deviation [SD]) of all participants was 50.6 (9.7) years. Mean systolic and diastolic BP across all participants were 131 (22) and 82 (12) $\mathrm{mmHg}$, respectively. Men had higher BP than women (133 vs. $130 \mathrm{mmHg}$, differences in the means $95 \% \mathrm{CI}$ : $3.0-3.5$ for systolic BP; and 83 vs. 81 , differences in the means 95\% CI: 1.4-1.6 for diastolic BP). BP was higher in participants with diabetes, and among those with CVD. $46 \%$ of the study population resided in rural communities, however, BP did not differ substantially by rural-urban residency $(\sim \mathrm{mmHg})$. Two in every five participants were hypertensive, but the prevalence of hypertension (and treatment) varied across income regions, ranging from $29.9 \%$ (4.4\%) in low-income to $49.6 \%$ (21.0\%) in upper middle-income countries. Details on the prevalence, awareness, treatment, and control of hypertension among PURE participants are provided elsewhere (Chow et al., 2013).

\subsection{Outdoor $P M_{2.5}$}

Fig. 1 illustrates the location of the PURE study communities and $\mathrm{PM}_{2.5}$ concentration estimates (Fig. 1A) and its distributions by country income status (Fig. 1B). Community long-term average outdoor $\mathrm{PM}_{2.5}$ levels (defined as a 3-year average PM centered on the year the community was enrolled) ranged from $<10 \mu \mathrm{g} / \mathrm{m}^{3}$ in Canada, Colombia, and Sweden to $>60 \mu \mathrm{g} / \mathrm{m}^{3}$ in Bangladesh, China, and UAE. Residents of communities in lower middle-income countries had highest $\mathrm{PM}_{2.5}$ exposures, largely driven by high exposures in communities in China. Levels were significantly higher on average in low-income and lower middle-income country communities than in upper middle- and high-income countries (46 vs. $\left.18 \mu \mathrm{g} / \mathrm{m}^{3}\right) . \mathrm{PM}_{2.5}$ concentrations were higher in urban $(40 \mu \mathrm{g} /$ $\mathrm{m}^{3}$ ) compared to rural $\left(32 \mu \mathrm{g} / \mathrm{m}^{3}\right)$ communities.

Selected demographic, health, and exposure characteristics of the participants by outdoor $\mathrm{PM}_{2.5}$ quartiles are summarized in Table 1. There were no clear-cut variations in $\mathrm{BP}$ by $\mathrm{PM}_{2.5}$ quartiles, although both systolic and diastolic BP were relatively lowest among participants whose community average $\mathrm{PM}_{2.5}$ levels fell within the second quartile $\left(\mathrm{Q}_{2}\right)$, and highest among those in the top 25th percentile $\left(Q_{4}\right)$ (Table 1$)$. However, hypertension and the use of anti-hypertensive medications were highest among those in the lower 25th percentile $\left(Q_{1}\right)$. Solid fuel use was relatively higher among those in the top 50th $\left(\mathrm{Q}_{3} \& \mathrm{Q}_{4}\right)$ percentile.

\subsection{Association of outdoor $P M_{2.5}$ with hypertension and $B P$}

Chronic $\mathrm{PM}_{2.5}$ exposure was associated with slightly increased odds of having hypertension in the entire cohort, with an adjusted odds ratio (OR) of 1.04 (95\% CI: 1.01, 1.07) per $10 \mu \mathrm{g} / \mathrm{m}^{3}$ increase in $\mathrm{PM}_{2.5}$ (Table 2). Higher ORs were observed at higher $\mathrm{PM}_{2.5}$ concentrations; the OR for Q4 was 1.36 (95\% CI: $1.10,1.69)$, Q3 was 1.31 (95\% CI: $1.08,1.58)$, and Q2 was 0.90 (95\% CI: $0.77,1.05)$ compared to Q1 as reference.

For BP parameters, we observed no associations in linear models (Table 1). However, we observed increased estimates for systolic and diastolic BP and MAP at the highest concentrations. For example, compared to Q1, systolic BP was $2.15 \mathrm{mmHg}$ higher (95\% 

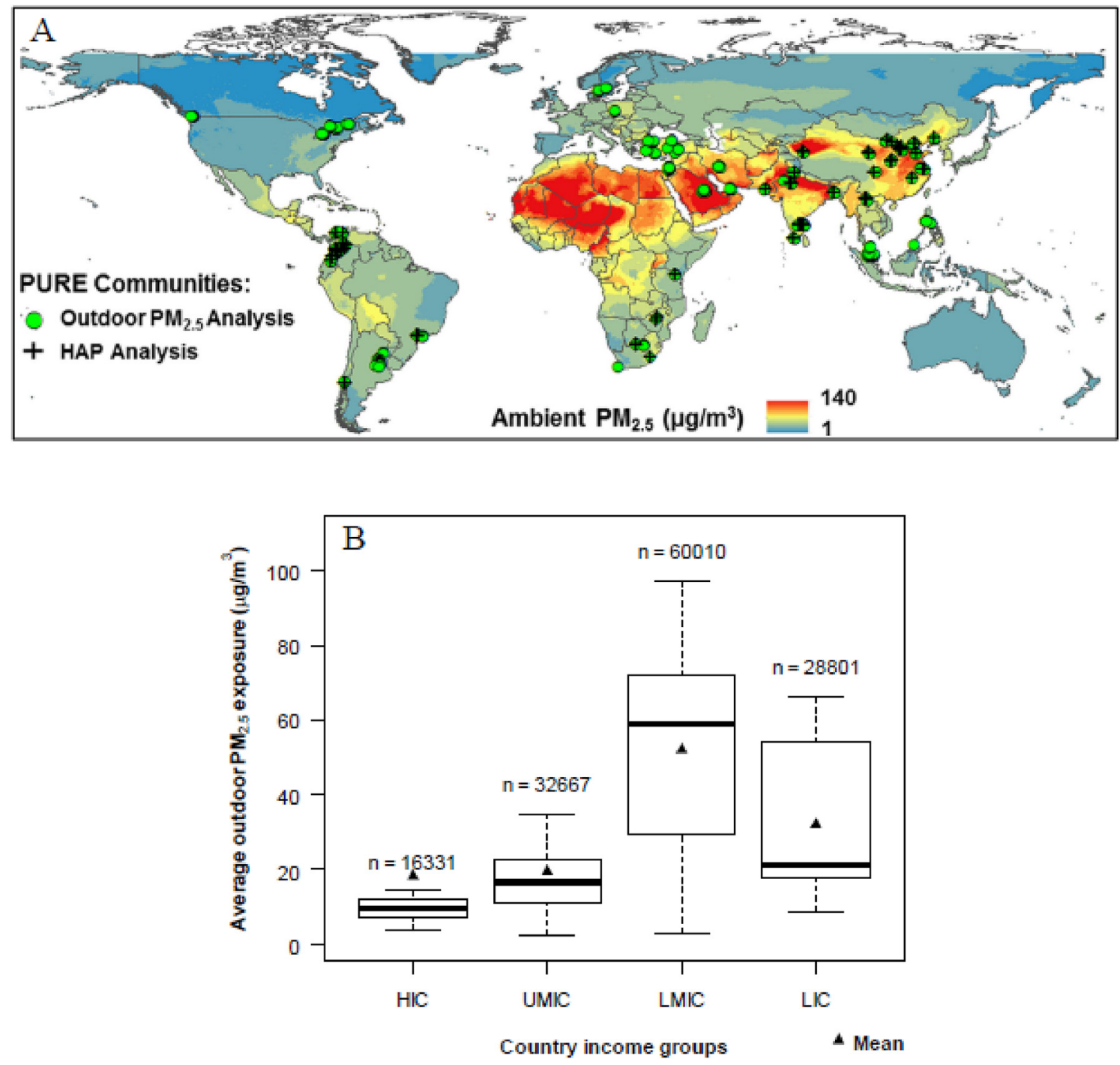

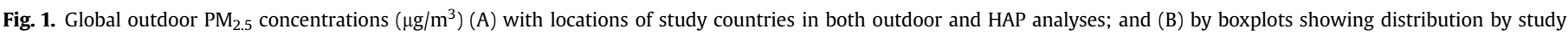

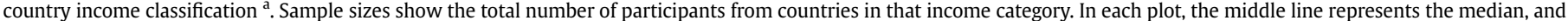

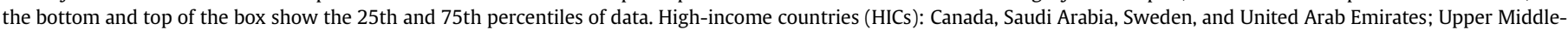

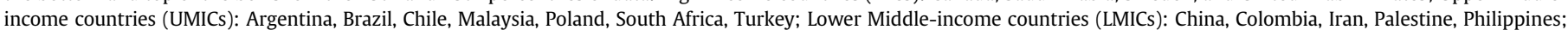

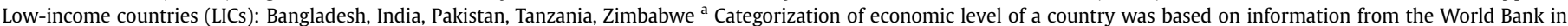
2006.

Table 2

Associations between outdoor $\mathrm{PM}_{2.5}$ (per $10 \mu \mathrm{g} / \mathrm{m}^{3}$ increase), use of solid fuels for cooking, versus clean fuels, and BP parameters and the odds of having hypertension.

\begin{tabular}{|c|c|c|c|c|c|c|}
\hline & No. samples & Systolic BP $\beta(95 \%$ CI $)$ & $\begin{array}{l}\text { Diastolic BP } \beta \\
(95 \% \mathrm{CI})\end{array}$ & $\begin{array}{l}\text { Pulse Pressure } \beta \\
(95 \% \mathrm{CI})\end{array}$ & $\begin{array}{l}\text { Mean Arterial Pressure } \\
\beta(95 \% \mathrm{CI})\end{array}$ & $\begin{array}{l}\text { Hypertension Odds } \\
\text { ratio }(95 \% \mathrm{CI})\end{array}$ \\
\hline \multicolumn{7}{|l|}{ Outdoor $\mathrm{PM}_{2.5}$} \\
\hline \multicolumn{7}{|l|}{ Unadjusted } \\
\hline Linear & 137,809 & $0.00(-0.04,0.04)$ & $0.01(-0.01,0.03)$ & $0.00(-0.03,0.02)$ & $0.01(-0.02,0.03)$ & $0.00(0.000 .01)$ \\
\hline Q1 & 34,267 & 0.0 & 0.0 & 0.0 & 0.0 & 1 \\
\hline Q2 & 32,009 & $-3.72(-5.89,-1.62)$ & $-1.42(-2.56,-0.27)$ & $-2.28(-3.75,-0.81)$ & $-2.19(-3.56,-0.82)$ & $0.80(0.68,0.94)$ \\
\hline Q3 & 35,511 & $0.72(-1.71,3.16)$ & $1.06(-0.27,2.40)$ & $-0.25(-1.96,1.45)$ & $0.94(-0.65,2.53)$ & $1.18(0.97,1.43)$ \\
\hline Q4 & 36,022 & $-0.35(-3.19,2.50)$ & $0.85(-0.71,2.41)$ & $-1.12(-3.11,0.87)$ & $0.45(-1.40,2.31)$ & $1.22(0.97,1.54)$ \\
\hline \multicolumn{7}{|l|}{ Adjusted } \\
\hline Linear & 137,809 & $0.01(-0.02,0.05)$ & $0.01(-0.01,0.03)$ & $0.00(-0.03,0.03)$ & $0.01(-0.01,0.04)$ & $1.04(1.01,1.07)$ \\
\hline Q1 & 34,267 & 0.0 & 0.0 & 0.0 & 0.0 & 1 \\
\hline Q2 & 32,009 & $-0.78(-2.73,1.17)$ & $-0.49(-1.58,0.61)$ & $-0.3(-1.73,1.14)$ & $-0.58(-1.85,0.69)$ & $0.90(0.77,1.05)$ \\
\hline Q3 & 35,511 & $3.72(1.37,6.07)$ & $1.61(0.29,2.93)$ & $2.15(0.42,3.87)$ & $2.31(0.77,3.84)$ & $1.31(1.08,1.58)$ \\
\hline Q4 & 36,022 & $2.15(-0.59,4.89)$ & $1.35(-0.2,2.89)$ & $0.84(-1.17,2.85)$ & $1.62(-0.17,3.4)$ & $1.36(1.10,1.69)$ \\
\hline \multicolumn{7}{|l|}{ Solid Fuel Use } \\
\hline Unadjusted & 43,313 & $-0.81(-0.81,0.26)$ & $-1.21(-1.50,-0.92)$ & $0.39(0.06,0.72)$ & $-1.08(-1.42,-0.73)$ & $0.90(0.86,0.95)$ \\
\hline Adjusted & 43,313 & $-0.48(-0.95,-0.01)$ & $-0.44(-0.72,-0.15)$ & $-0.05(-0.37,0.27)$ & $-0.45(-0.78,-0.13)$ & $0.93(0.88,0.99)$ \\
\hline
\end{tabular}


Table 3

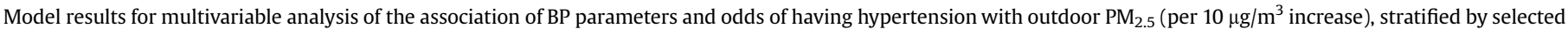
variables. $^{\text {a }}$

\begin{tabular}{|c|c|c|c|c|c|c|}
\hline \multirow[t]{2}{*}{ Entire sample } & \multirow{2}{*}{$\begin{array}{l}\text { No. samples } \\
137,809\end{array}$} & \multirow{2}{*}{$\begin{array}{l}\text { Systolic BP } \beta \\
\frac{(95 \% \mathrm{CI})}{0.13(-0.24,0.49)}\end{array}$} & \multirow{2}{*}{$\begin{array}{l}\text { Diastolic BP } \beta \\
(95 \% \mathrm{CI}) \\
0.12(-0.09,0.33)\end{array}$} & \multirow{2}{*}{$\begin{array}{l}\text { Pulse Pressure } \beta \\
(95 \% \mathrm{CI}) \\
0.0(-0.26,0.26)\end{array}$} & \multirow{2}{*}{$\begin{array}{l}\text { Mean Arterial Pressure } \\
\frac{\beta(95 \% \mathrm{CI})}{0.12(-0.12,0.36)}\end{array}$} & \multirow{2}{*}{$\begin{array}{l}\text { Hypertension Odds } \\
\text { ratio }(95 \% \mathrm{CI})\end{array}$} \\
\hline & & & & & & \\
\hline \multicolumn{7}{|l|}{ Gender } \\
\hline Female & 79,950 & $0.11(-0.29,0.50)$ & $0.17(-0.04,0.39)$ & $-0.07(-0.35,0.20)$ & $0.15(-0.11,0.41)$ & $1.03(0.99,1.07)$ \\
\hline Male & 57,859 & $0.26(-0.09,0.62)$ & $0.16(-0.05,0.38)$ & $0.1(-0.16,0.35)$ & $0.20(-0.05,0.44)$ & $1.05(1.01,1.09)$ \\
\hline \multicolumn{7}{|l|}{ Residence } \\
\hline Urban & 74,601 & $0.32(-0.10,0.73)$ & $0.17(-0.08,0.42)$ & $0.14(-0.22,0.49)$ & $0.22(-0.05,0.50)$ & $1.04(1.00,1.08)$ \\
\hline Rural & 63,208 & $0.19(-0.37,0.75)$ & $0.29(-0.03,0.61)$ & $-0.11(-0.48,0.26)$ & $0.25(-0.13,0.63)$ & $1.07(1.02,1.12)$ \\
\hline \multicolumn{7}{|l|}{ Hypertension } \\
\hline No & 82,346 & $0.14(-0.08,0.36)$ & $0.15(0.01,0.29)$ & $-0.01(-0.19,0.16)$ & $0.15(0.00,0.30)$ & NA \\
\hline Yes & 55,463 & $-0.05(-0.35,0.25)$ & $0.05(-0.13,0.22)$ & $-0.12(-0.45,0.2)$ & $0.02(-0.15,0.19)$ & NA \\
\hline \multicolumn{7}{|c|}{ Anti-hypertensive medication use } \\
\hline No & 118,721 & $0.16(-0.20,0.51)$ & $0.17(-0.04,0.37)$ & $-0.01(-0.27,0.25)$ & $0.16(-0.07,0.40)$ & $1.03(1.00,1.07)$ \\
\hline Yes & 19,088 & $-0.29(-0.82,0.25)$ & $-0.22(-0.51,0.07)$ & $-0.09(-0.47,0.28)$ & $-0.26(-0.60,0.09)$ & NA \\
\hline \multicolumn{7}{|l|}{ Heart disease } \\
\hline No & 132,058 & $0.12(-0.24,0.49)$ & $0.13(-0.08,0.33)$ & $-0.01(-0.27,0.25$ & $0.13(-0.12,0.37)$ & $1.03(1.00,1.07)$ \\
\hline Yes & 5568 & $0.07(-0.57,0.72)$ & $0.15(-0.19,0.50)$ & $-0.05(-0.50,0.40)$ & $0.11(-0.30,0.53)$ & $1.06(1.00,1.13)$ \\
\hline \multicolumn{7}{|l|}{ Diabetes mellitus } \\
\hline No & 126,536 & $0.13(-0.23,0.49)$ & $0.13(-0.08,0.33)$ & $-0.01(-0.27,0.25)$ & $0.13(-0.11,0.37)$ & $1.03(1.00,1.07)$ \\
\hline Yes & 11,120 & $0.37(-0.16,0.91)$ & $0.35(0.04,0.65)$ & $0.03(-0.37,0.42)$ & $0.35(0.00,0.70)$ & $1.06(1.01,1.11)$ \\
\hline \multicolumn{7}{|l|}{ BMI } \\
\hline Underweight & 7075 & $0.87(0.27,1.46)$ & $0.76(0.40,1.12)$ & $0.01(-0.34,0.36)$ & $0.80(0.39,1.21)$ & $1.17(1.11,1.25)$ \\
\hline Normal weight & 58,189 & $0.05(-0.33,0.42)$ & $0.1(-0.11,0.32)$ & $-0.05(-0.31,0.22)$ & $0.08(-0.17,0.33)$ & $1.03(0.99,1.07)$ \\
\hline Overweight & 47,896 & $0.09(-0.28,0.46)$ & $0.12(-0.1,0.35)$ & $-0.03(-0.30,0.23)$ & $0.11(-0.14,0.36)$ & $1.03(1.00,1.07)$ \\
\hline Obese & 24,649 & $0.10(-0.33,0.54)$ & $0.07(-0.18,0.33)$ & $0.02(-0.31,0.34)$ & $0.09(-0.20,0.38)$ & $1.05(1.01,1.09)$ \\
\hline \multicolumn{7}{|l|}{ Smoking status } \\
\hline Never & 16,094 & $-0.08(-0.55,0.38)$ & $-0.03(-0.31,0.25)$ & $-0.08(-0.4,0.25)$ & $-0.05(-0.37,0.27)$ & $1.01(0.96,1.06)$ \\
\hline Ever & 121,715 & $0.13(-0.25,0.50)$ & $0.14(-0.07,0.35)$ & $-0.02(-0.29,0.25)$ & $0.13(-0.11,0.38)$ & $1.03(1.00,1.07)$ \\
\hline \multicolumn{7}{|l|}{ Alcohol use } \\
\hline Never & 6292 & $0.00(-0.54,0.53)$ & $-0.03(-0.37,0.31)$ & $0.05(-0.32,0.42)$ & $-0.02(-0.40,0.36)$ & $0.98(0.93,1.03)$ \\
\hline Ever & 131,517 & $0.07(-0.30,0.44)$ & $0.1(-0.11,0.31)$ & $-0.03(-0.30,0.23)$ & $0.09(-0.15,0.33)$ & $1.03(0.99,1.06)$ \\
\hline \multicolumn{7}{|l|}{ Age (years) } \\
\hline$\leq 50$ & 70,376 & $0.30(-0.05,0.64)$ & $0.27(0.06,0.48)$ & $0.03(-0.22,0.28)$ & $0.28(0.05,0.52)$ & $1.06(1.02,1.10)$ \\
\hline$>50$ & 67,433 & $-0.03(-0.46,0.41)$ & $0.09(-0.13,0.32)$ & $-0.12(-0.43,0.19)$ & $0.05(-0.23,0.32)$ & $1.01(0.98,1.05)$ \\
\hline Healthy participants ${ }^{\mathrm{b}}$ & 108,656 & $0.14(-0.22,0.49)$ & $0.16(-0.04,0.37)$ & $-0.03(-0.29,0.23)$ & $0.15(-0.08,0.39)$ & $1.03(1.00,1.07)$ \\
\hline
\end{tabular}

a Model 3: age, sex and race/ethnicity, education (none, primary, secondary/high school/higher secondary, trade school, college/university, unknown), marital status

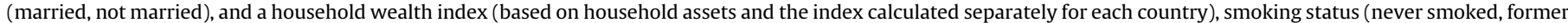

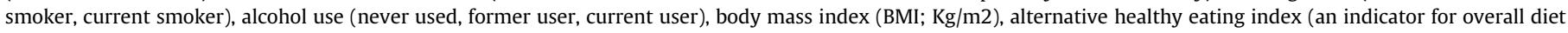

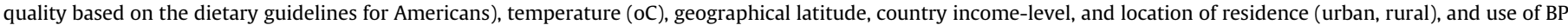
lowering medication (medication use, no medication use). All models included random intercepts for country and community.

b Participants who were free of CVD, diabetes mellitus, and did not take BP medication.

$\mathrm{CI}:-0.59,4.89)$ in $\mathrm{Q} 4,3.72 \mathrm{mmHg}$ higher $(95 \% \mathrm{CI}: 1.37,6.07)$ in $\mathrm{Q} 3$, and $-0.78 \mathrm{mmHg}(95 \% \mathrm{CI}:-2.73,1.17)$ in Q2 (Table 2).

In stratified analyses (Table 3) using the full model (Model 3), we found 1.08 (95\% CI: 1.02, 1.12) higher OR for hypertension in rural residents compared to weak 1.04 (95\% CI: $1.00,1.08)$ in urban residents. Further, we found higher ORs for men (1.05; 95\% CI: 1.01, $1.09)$, individuals younger than age 50 (1.06; $95 \% \mathrm{CI}: 1.02,1.10)$, those with diabetes $(1.06$; $95 \% \mathrm{CI}: 1.01,1.11)$, and in those who were underweight $(1.17 ; 95 \% \mathrm{CI}$ : $(1.11,1.25)$ and obese $(1.05 ; 95 \% \mathrm{CI}: 1.01$, 1.09) (Table 3). For other BP parameters we observed weak positive associations between outdoor $\mathrm{PM}_{2.5}$ (per $10 \mu \mathrm{g} / \mathrm{m}^{3}$ increase) and diastolic BP among subjects who were diabetic $(0.35 \mathrm{mmHg} ; 95 \%$ CI: $0.04,0.65)$; were younger than 50 years of age $(0.27 \mathrm{mmHg} ; 95 \%$ $\mathrm{CI}: 0.06,0.48)$; and were underweight $(0.76 \mathrm{mmHg} ; 95 \% \mathrm{CI}: 0.40$, 1.12) (Table 3). Among those underweight, we also observed similar weak positive association for systolic $\mathrm{BP}(0.87 \mathrm{mmHg}$; $95 \% \mathrm{CI}: 0.27$, 1.46).

\subsection{Household air pollution}

A subset of 43,313 participants in 192 rural communities in 10 countries constituted the population used in the HAP analysis. The ten countries included here had $>10 \%$ solid fuel use prevalence in at least one study center at study baseline. Overall, close to $70 \%$ of the rural population in this sample used solid fuel as their primary cooking fuel. Across countries, the predominant cooking fuel types in this rural sample were wood (32\%), gas (27\%) and coal (20\%). Use of coal was highest (>60\%) in parts of China while wood was dominant in Pakistan, India, Zimbabwe and Tanzania. Selected demographic, health, and exposure characteristics of the participants by solid versus clean fuels for cooking are summarized in Table 1. Mean age and proportion of women were similar between solid and clean fuel users. The share of individuals living with hypertension (and its treatment) and diabetes were higher in clean fuel users (42\%) compared to solid fuel users (34\%). Smoking was more prevalent in those cooking with solid fuels than clean fuels. Outdoor $\mathrm{PM}_{2.5}$ was also higher in communities where solid fuel was predominant (Table 1). By individual fuel category, mean systolic BP did not follow any patterns; it was highest among those who cooked with electricity (137 $\mathrm{mmHg}$ ), approximately $12 \mathrm{mmHg}$ higher than in wood users (who had lowest mean systolic BP), followed by coal and shrub/grass. Diastolic BP was also higher by $9 \mathrm{mmHg}$ among those who cooked primarily with electricity compared to wood. 


\subsection{Association of household solid fuel use with hypertension and $B P$}

The inverse relation between clean fuels and BP in our HAP dataset persisted in the multivariable analyses. We observed lower odds of having hypertension among those cooking primarily with solid fuels compared with clean fuels (OR $=0.93 ; 95 \% \mathrm{CI}$ : $0.88,0.99$ ) (Table 2). The overall initial mean difference in BP levels among individuals who cooked with solid fuels was significantly lower than among those who used clean fuels (130 vs. $133 \mathrm{mmHg}$ for systolic BP [95\% CI: 2.7, 3.6] and 81 vs. $83 \mathrm{mmHg}$ for diastolic BP [95\% CI: 1.9, 2.4]). This lower BP among solid fuel users also persisted in the adjusted models. In the full model (Model 3), use of solid fuel was associated with $0.51 \mathrm{mmHg}$ lower systolic BP (95\% CI: -0.99, -0.03), $0.46 \mathrm{mmHg}$ lower diastolic BP (95\% CI: $-0.75,-0.18)$, and 0.48 lower MAP (95\% CI: $-0.81,-0.15$ ) (Fig. S2).

Stratified analyses of BP and HAP did not show clear patterns by individual, household or community characteristics (Table 4). Use of solid fuels was associated with lower odds of hypertension in men, those younger than age 50, and among smokers, and alcohol users by approximately $6-11 \%$ (Table 4). It was about $0.47-0.87 \mathrm{mmHg}$ lower for other BP parameters.

In sensitivity analysis we used the full model (Model 3) to pool center-specific estimates through random-effects meta-analysis, and observed similar lower pooled odds of hypertension among solid fuel users when compared to clean fuels (Pooled OR $=0.93$; $95 \%$ CI: 0.86, 1.00) (Fig. 2). Similar findings were observed for other BP parameters in the center pooled estimates (Fig. S3). There was statistically significant heterogeneity across study centers, and within and between countries, especially for systolic BP. For instance, in China, results generally demonstrate positive associations for systolic BP while centers in India and other countries showed negative associations (Fig. S3).

\subsection{Joint outdoor $P M_{2.5}$ and HAP exposures versus BP parameters}

The interaction term between outdoor $\mathrm{PM}_{2.5}$ and solid fuel use for cooking was not statistically significant. For outdoor $\mathrm{PM}_{2.5}$ among only clean fuel (electricity/gas) users, we observed small positive associations for systolic $(0.43 \mathrm{mmHg} ; 95 \% \mathrm{CI}: 0.06,0.81)$, diastolic BP (0.30 mmHg; $95 \% \mathrm{CI}: 0.08,0.52)$, and MAP $(0.35 \mathrm{mmHg}$; $95 \% \mathrm{CI}: 0.10,0.59)$. For every $10 \mu \mathrm{g} / \mathrm{m}^{3}$ increase in outdoor $\mathrm{PM}_{2.5}$, there was 1.34 (95\%CI: $1.12,1.59)$ higher odds of having hypertension among those who cooked primarily with clean fuels compared to 1.17 (95\%CI: $0.95,1.46$ ) among solid fuel users (Table S1). We found no differences in the associations for solid fuel use among either the lowest or the highest $\mathrm{PM}_{2.5}$ quartiles (Table S1) for BP.

\section{Discussion}

This is the first multi-country and multi-center study of the

Table 4

Model results for multivariable analysis of the association of BP parameters and odds of hypertension with solid fuel use, stratified by selected variables. ${ }^{\mathrm{a}}$

\begin{tabular}{|c|c|c|c|c|c|c|}
\hline \multirow[t]{2}{*}{ Entire sample } & \multirow{2}{*}{$\frac{\text { No. samples }}{43,313}$} & \multirow{2}{*}{$\begin{array}{l}\text { Systolic BP } \beta \\
\frac{(95 \% \mathrm{CI})}{-0.48(-0.95,-0.01)}\end{array}$} & \multirow{2}{*}{$\begin{array}{l}\text { Diastolic BP } \beta \\
(95 \% \mathrm{CI}) \\
-0.44(-0.72,-0.15)\end{array}$} & \multirow{2}{*}{$\begin{array}{l}\text { Pulse Pressure } \beta \\
(95 \% \mathrm{CI}) \\
-0.05(-0.37,0.27)\end{array}$} & \multirow{2}{*}{$\begin{array}{l}\text { Mean Arterial Pressure } \\
\frac{\beta(95 \% \mathrm{CI})}{-0.45(-0.78,-0.13)}\end{array}$} & \multirow{2}{*}{$\begin{array}{l}\text { Hypertension Odds } \\
\text { ratio }(95 \% \mathrm{CI}) \\
0.93(0.88,0.99)\end{array}$} \\
\hline & & & & & & \\
\hline \multicolumn{7}{|l|}{ Gender } \\
\hline Female & 24,966 & $-0.26(-0.90,0.38)$ & $-0.19(-0.56,0.18)$ & $-0.08(-0.51,0.35)$ & $-0.21(-0.64,0.22)$ & $0.96(0.88,1.04)$ \\
\hline Male & 18,347 & $-0.87(-1.57,-0.17)$ & $-0.82(-1.26,-0.38)$ & $-0.05(-0.51,0.41)$ & $-0.84(-1.33,-0.34)$ & $0.90(0.83,0.99)$ \\
\hline \multicolumn{7}{|l|}{ Hypertension } \\
\hline No & 27,430 & $-0.54(-0.87,-0.20)$ & $-0.38(-0.63,-0.14)$ & $-0.17(-0.42,0.09)$ & $-0.43(-0.68,-0.19)$ & NA \\
\hline Yes & 15,883 & $0.35(-0.39,1.09)$ & $-0.02(-0.45,0.41)$ & $0.40(-0.19,1.00)$ & $0.10(-0.37,0.58)$ & NA \\
\hline \multicolumn{7}{|c|}{ Anti-hypertensive medication use } \\
\hline No & 39,547 & $-0.71(-1.19,-0.22)$ & $-0.46(-0.76,-0.17)$ & $-0.25(-0.58,0.07)$ & $-0.54(-0.88,-0.20)$ & $0.94(0.88,0.99)$ \\
\hline Yes & 3766 & $1.25(-0.48,2.99)$ & $-0.3(-1.28,0.68)$ & $1.59(0.36,2.82)$ & $0.21(-0.94,1.36)$ & NA \\
\hline \multicolumn{7}{|l|}{ Heart disease } \\
\hline No & 41,653 & $-0.45(-0.93,0.02)$ & $-0.43(-0.72,-0.14)$ & $-0.03(-0.35,0.29)$ & $-0.44(-0.77,-0.11)$ & $0.89(0.61,1.30)$ \\
\hline Yes & 1578 & $-1.57(-4.42,1.29)$ & $-0.86(-2.55,0.83)$ & $-0.67(-2.63,1.29)$ & $-1.08(-3.02,0.85)$ & $0.94(0.88,1.00)$ \\
\hline \multicolumn{7}{|l|}{ Diabetes mellitus } \\
\hline No & 41,209 & $-0.47(-0.96,0.01)$ & $-0.48(-0.77,-0.18)$ & $-0.01(-0.33,0.32)$ & $-0.48(-0.81,-0.14)$ & $0.80(0.61,1.05)$ \\
\hline Yes & 2034 & $0.15(-2.16,2.46)$ & $0.11(-1.18,1.4)$ & $-0.09(-1.71,1.52)$ & $0.14(-1.38,1.66)$ & $0.95(0.89,1.01)$ \\
\hline \multicolumn{7}{|l|}{ BMI } \\
\hline Underweight & 4612 & $-0.82(-2.56,0.93)$ & $-0.19(-1.27,0.88)$ & $-0.64(-1.79,0.52)$ & $-0.4(-1.62,0.82)$ & $0.92(0.70,1.20)$ \\
\hline Normal weight & 23,300 & $-0.62(-1.26,0.02)$ & $-0.43(-0.81,-0.05)$ & $-0.20(-0.62,0.22)$ & $-0.49(-0.93,-0.06)$ & $0.94(0.87,1.03)$ \\
\hline Overweight & 11,854 & $-0.14(-1.01,0.73)$ & $-0.4(-0.92,0.12)$ & $0.24(-0.34,0.83)$ & $-0.31(-0.91,0.28)$ & $0.93(0.84,1.03)$ \\
\hline Obese & 3547 & $-0.59(-2.32,1.14)$ & $-0.4(-1.42,0.63)$ & $-0.18(-1.36,0.99)$ & $-0.47(-1.65,0.71)$ & $0.92(0.77,1.11)$ \\
\hline \multicolumn{7}{|l|}{ Smoking status } \\
\hline Never & 2524 & $0.13(-1.89,2.15)$ & $0.00(-1.25,1.25)$ & $0.06(-1.28,1.4)$ & $0.05(-1.37,1.46)$ & $0.97(0.76,1.25)$ \\
\hline Ever & 40,789 & $-0.54(-1.03,-0.06)$ & $-0.49(-0.78,-0.20)$ & $-0.06(-0.39,0.26)$ & $-0.51(-0.84,-0.17)$ & $0.94(0.88,1.00)$ \\
\hline \multicolumn{7}{|l|}{ Alcohol use } \\
\hline Never & 1780 & $0.48(-1.97,2.92)$ & $0.14(-1.37,1.64)$ & $0.30(-1.30,1.90)$ & $0.25(-1.46,1.96)$ & $0.80(0.59,1.08)$ \\
\hline Ever & 41,533 & $-0.54(-1.02,-0.05)$ & $-0.47(-0.76,-0.18)$ & $-0.07(-0.40,0.25)$ & $-0.50(-0.83,-0.16)$ & $0.94(0.88,0.99)$ \\
\hline \multicolumn{7}{|l|}{ Age (years) } \\
\hline$\leq 50$ & 24,230 & $-0.72(-1.28,-0.16)$ & $-0.55(-0.92,-0.19)$ & $-0.19(-0.55,0.17)$ & $-0.61(-1.02,-0.20)$ & $0.89(0.82,0.97)$ \\
\hline$>50$ & 19,083 & $-0.31(-1.12,0.51)$ & $-0.35(-0.79,0.10)$ & $0.04(-0.53,0.60)$ & $-0.34(-0.87,0.20)$ & $0.98(0.90,1.06)$ \\
\hline Healthy participants ${ }^{b}$ & 36,947 & $-0.65(-1.15,-0.14)$ & $-0.46(-0.76,-0.15)$ & $-0.2(-0.53,0.14)$ & $-0.52(-0.87,-0.17)$ & $0.95(0.89,1.01)$ \\
\hline
\end{tabular}

All models included random intercepts for country and center.

a Model 3: age, sex and race/ethnicity, education (none, primary, secondary/high school/higher secondary, trade school, college/university, unknown), marital status

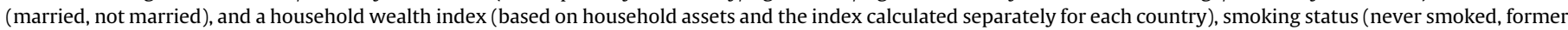

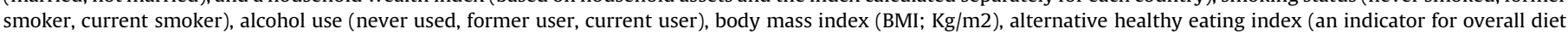

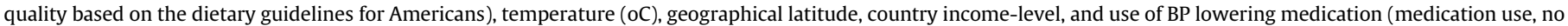
medication use).

b Participants who were free of CVD, diabetes mellitus, and did not take BP medication. 


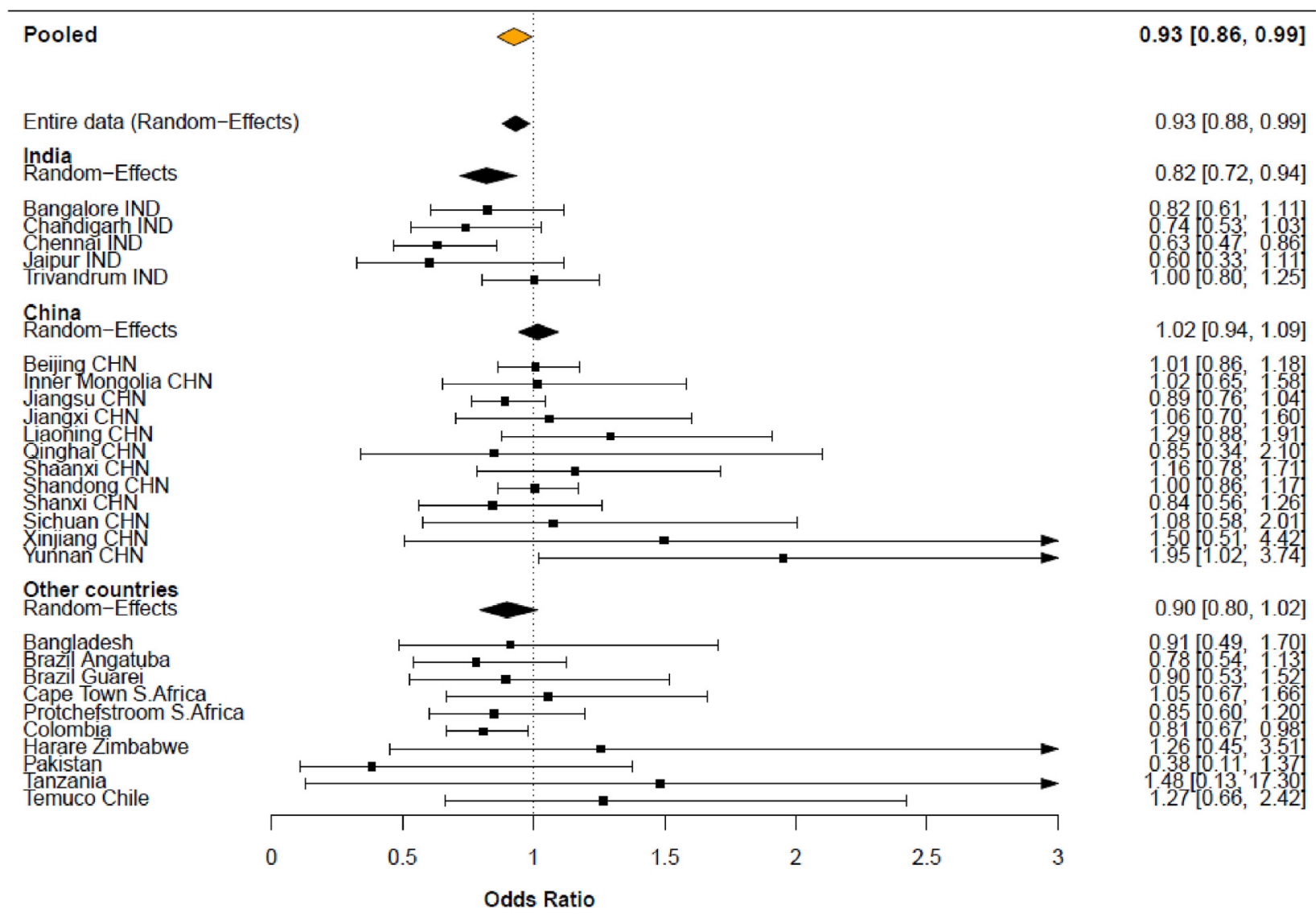

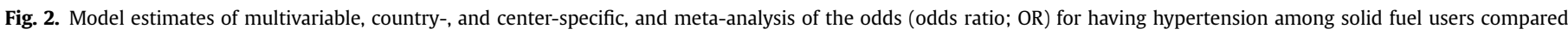

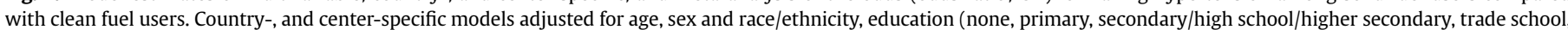

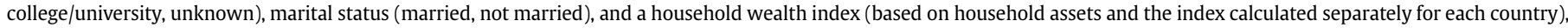

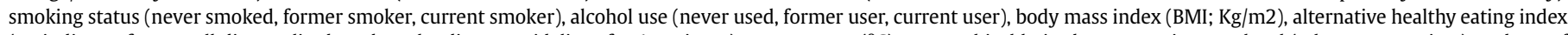

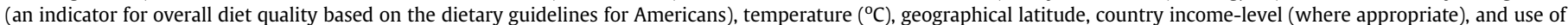
BP lowering medication (medication use, no medication use). Models included random intercepts for either country and/or study center where appropriate.

relationship between chronic air pollution exposure, including both outdoor $\mathrm{PM}_{2.5}$ and household solid fuel use for cooking, with BP. We examined 137,809 adults aged 35-70 years from 640 urban and rural communities in 21 countries, capturing a wide range of outdoor $\mathrm{PM}_{2.5}$ exposures, household cooking settings, and diverse individual and community characteristics. For outdoor $\mathrm{PM}_{2.5}$, we observed increased odds of hypertension 1.04 (95\% CI: 1.01, 1.07) per $10 \mu \mathrm{g} / \mathrm{m}^{3}$ increase in $\mathrm{PM}_{2.5}$. BP measures demonstrated nonlinear relationships with an indication of positive associations at higher $\mathrm{PM}_{2.5}$ concentrations. In contrast, for HAP, we observed indications of decreases in odds of hypertension, and decreases in systolic and diastolic BP among solid fuel users, but these associations varied notably by study country and study center. The associations between HAP and BP likely reflect residual confounding in this multi-country analysis, especially in relation to affluence, as we observed significantly higher baseline systolic and diastolic BP and hypertension prevalence among individuals using clean fuels (gas/ electricity) compared to solid fuels.

\subsection{Chronic $P M_{2.5}-B P$ association}

While evidence exists for short-term exposures (Brook et al., 2010; Newby et al., 2015; Shah et al., 2015; Du et al., 2016), data on chronic outdoor $\mathrm{PM}_{2.5}$ exposures and hypertension and BP are limited and inconsistent (Chan et al., 2015; Fuks et al., 2011; Zhang et al., 2018; Auchincloss et al., 2008; Fuks et al., 2016; Cai et al., 2016; Liang et al., 2014; Honda et al., 2018; Xie et al., 2018; Bo et al., 2019). The few previous studies of chronic exposures were conducted mainly in a single country/city/center setting. While such homogenous population helps in reducing ecological confounding, the PM exposure levels are considerably lower or cover narrower ranges of exposure. In our multi-country and center analyses, which relied on long-term averaged exposures, and with one of the widest range of exposures $\left(\sim 3-97 \mu \mathrm{g} / \mathrm{m}^{3}\right)$, the results demonstrate positive associations with hypertension, as reported in some studies (Zhang et al., 2018; Honda et al., 2018; Xie et al., 2018), but which is also contrary to findings elsewhere (Chan et al., 2015; Fuks et al., 2016). The associations with BP itself were evident only at higher PM concentrations. Evidence of non-linear relationships between PM and BP likely made it difficult for us to detect associations in our multi-country, multi-center study as countries and centers within countries potentially occupy different parts of the exposure-response curve. We accounted for country income level, along with other factors like urban-rural location, but countries/centers likely have BP levels that are lower/higher than would be predicted based on PM alone.

A few population-based cohort studies from the US (Chan et al., 2015), Germany (Fuks et al., 2011), and Taiwan (Zhang et al., 2018; Chuang et al., 2011) found that long-term average $\mathrm{PM}_{2.5}$ was modestly associated with BP. Unlike these single setting studies, 
$\mathrm{PM}_{2.5}$ across our 21 study countries (on 5 continents) likely represented more heterogeneous mixtures that originated from more diverse sources (e.g. traffic, biomass, coal, and crustal dust) than in previous study settings (mostly traffic). It is possible that combustion PM, as proxied by black carbon (Baumgartner et al., 2014), has a stronger association with BP parameters than the total mass, hence our weak findings using data from diverse locations globally.

In general, the body of evidence so far suggest that the impact of chronic $\mathrm{PM}_{2.5}$ exposure may be stronger for hypertension than for BP parameters. Even in the extreme case of chronic smoking, which exposes smokers to high concentrations of PM, and is a proven risk factor for heart attacks and stroke, there is not a conclusive link to elevated BP. Epidemiological studies mostly found that BP levels among cigarette smokers were the same as or lower than those of non-smokers; and if any, the independent chronic effect of smoking on BP is small or clinically insignificant (Green et al., 1986), which may be the case for the impact of long-term PM exposure on BP.

\subsection{Solid fuel use-BP association}

There are few large epidemiological studies of HAP and BP (McCracken et al., 2012; Young et al., 2019; Yan et al., 2016; Abtahi et al., 2017), but fewer multi-country analysis (McCracken et al., 2012; Arku et al., 2017). Contrary to our study, a recent multicountry analyses of nationally representative and internationally comparable data for younger women (aged 15-49) found links between history of solid fuel use and small increases in BP and odds of hypertension (Arku et al., 2017). Cook-stove intervention studies in Latin America have reported larger associations between decreased BP in women with reduced exposure from household smoke (McCracken et al., 2007; McCracken et al., 2012; Alexander et al., 2015), and personal exposure studies of rural women also indicated evidence of associations between acute exposure to solid fuel combustion-related air pollutants and BP in China (Baumgartner et al., 2011) and Ghana (Quinn et al., 2016). In our study of 43,313 rural residents from 10 countries, we found an indication of lower BP among solid fuel users when compared to electricity/gas users, but with significant heterogeneity by centers and country; with generally positive associations for systolic BP in China and negative associations in India and in other countries. The positive association with systolic BP in China seems to be in accordance with findings of other studies conducted in China (Baumgartner et al., 2011; Baumgartner et al., 2014; Yan et al., 2016; Lee et al., 2012).

Overall, unadjusted mean BP across our study countries is low, and hypertension prevalence was very low in solid fuel users. For instance, $34 \%$ of solid fuels users, compared to $42 \%$ of clean fuel users, had hypertension; and the mean systolic/diastolic BP in solid fuels users was 130/81 which was significantly lower when compared to $133 / 83$ in the clean fuel group. It appears that solid fuel use, and thus HAP exposure in this cohort may be inversely correlated with other BP and hypertension risk factors, even after our comprehensive use of individual, household and community covariates, as was suggestive in smokers compared with nonsmokers (Green et al., 1986).

\subsection{Strengths and limitation}

The main strength of our study was its size and global scope, which enabled us to examine long-term average $\mathrm{PM}_{2.5}$ concentrations over the full global exposure distribution (range: 3-97 $\mu \mathrm{g}$ / $\mathrm{m}^{3}$ ), and with history of solid fuel use across multiple sites in different countries. Our data also included a wide range of individual-, household-, and community-level covariates on participants from both rural and urban communities. Our BP measures were also collected using a standardized protocol across study centers.

However, given the global nature of our analysis, there are also important limitations that must be considered. First, the diversity of sites in our study is a weakness in itself when making inference as adjustments such as country random effects will not remove all the ecological residual confounding. Residual confounding is a concern, especially for the HAP analysis given the larger baseline differences between solid and clean fuel users. While we included a comprehensive set of confounding factors, we could not account for personal or occupational $\mathrm{PM}_{2.5}$ exposures. It would be too costly and logistically prohibitive to conduct detailed personal monitoring in a large multi-country study as ours, particularly in centers where both household and outdoor sources are related. Studies of actual personal exposure measurement have demonstrated wide variations in $\mathrm{PM}_{2.5}$ among individuals living in the same community due to local emission sources and personal time activity (Baumgartner et al., 2011; Arku et al., 2015). By relying on 3-year average outdoor $\mathrm{PM}_{2.5}$ and on proxy indicators for HAP, our study likely captured only regional differences in exposures, with no information on between-persons variations among participants in the same community. Consequently, exposure errors stemming from variability in individual's long-term average exposures remain; but this also applies equally to all study communities and across the exposed versus unexposed groups. However, our $\mathrm{PM}_{2.5}$ predictions assigned at a $1 \times 1 \mathrm{~km}$ resolution potentially minimized the magnitude of the misclassified exposures.

Similarly, we used surrogate measures to assess HAP, which likely led to large exposure misclassification stemming from factors like stove stacking, ventilation, cooking practices, and emissions from neighbors' cookstoves, just to name a few (Smith et al., 2014; Bruce et al., 2015; Clark et al., 2013). Nevertheless, history of solid fuel use for cooking is a commonly used metric in large HAP epidemiologic studies (Smith et al., 2014) and our center metaanalysis approach yielded similar results as the overall analyses. Further, although the sampling frame in each study country was not nationally representative, it was shown that the overall prevalence of hypertension was similar to global estimates (Chow et al., 2013). We could not account for acute temperature and $\mathrm{PM}_{2.5}$ exposures, which might be partially responsible for changes in BP on the day of measurement (Modesti, 2013; Lewington et al., 2012). Importantly, we observed large initial differences in mean BP between individuals using solid fuel for cooking $(130 / 81 \mathrm{mmHg}$ ) compared to individuals using electricity or gas (133/83 $\mathrm{mmHg}$ ). BP is known to vary with diet, sedentary lifestyle, and other individual-level characteristics (e.g. BMI) that are related to low socio-economic status or poverty, which are also likely highly related to solid fuel use. Including covariates in the model may not totally control for such confounding effects. Residual confounding of our HAP results is therefore a possibility, but this would similarly be a limitation in any large existing studies of HAP and BP.

\subsection{Conclusion}

In this large international multi-center study, chronic exposure to outdoor $\mathrm{PM}_{2.5}$ was associated with increased odds of hypertension and small increases in BP at higher exposure levels, while HAP from cooking with solid fuels showed small decreases in odds of hypertension and BP, but the associations were inconsistent across countries and sub-populations. Future longitudinal analyses within the PURE cohort with center specific quantitative exposure data will clarify these findings. 


\section{Contributors}

REA, MB, and PH conceived and design analysis. REA conducted analyses and wrote the first draft. REA, MB, SY, and PH wrote final draft. PURE study team contributing authors read and contributed to writing and interpretation of manuscript (see SI for Other PURE study team contributing authors).

\section{Statement on data}

Data used in this analysis is part of a large international cohort. Data could be requested directly from the Project site (http://www. phri.ca/pure/).

\section{Declaration of competing interest}

We have no actual or potential competing financial interests.

\section{Acknowledgments}

This work was supported by the Canadian Institutes of Health Research [grant \#136893]; by the Office of The Director, National Institutes of Health of the National Institutes of Health [Award Number DP5OD019850]; and by the Michael Smith Foundation for Health Research Trainee Award [Award Number 28160]. The content is solely the responsibility of the authors and does not necessarily represent the official views of the National Institutes of Health or the Canadian Institutes of Health Research. Dr S Yusuf is supported by the Mary W Burke endowed chair of the Heart and Stroke Foundation of Ontario. Additional funding supports are found in the Appendix.

\section{Appendix A. Supplementary data}

Supplementary data to this article can be found online at https://doi.org/10.1016/j.envpol.2020.114197.

\section{References}

Abtahi, M., Koolivand, A., Dobaradaran, S., Yaghmaeian, K., Mohseni-Bandpei, A., Khaloo, S.S., et al., 2017. National and sub-national age-sex specific and causespecific mortality and disability-adjusted life years (DALYs) attributable to household air pollution from solid cookfuel use (HAP) in Iran, 1990-2013. Environ. Res. 156, 87-96.

Alexander, D., Larson, T., Bolton, S., Vedal, S., 2015. Systolic blood pressure changes in indigenous Bolivian women associated with an improved cookstove intervention. Air Qual. Atmos. Health 8 (1), 47-53.

Arku, R.E., Dionisio, K.L., Hughes, A.F., Vallarino, J., Spengler, J.D., Castro, M.C., et al., 2015. Personal particulate matter exposures and locations of students in four neighborhoods in Accra, Ghana. J. Expo. Sci. Environ. Epidemiol. 25 (6), $557-566$.

Arku, R.E., Ezzati, M., Baumgartner, J., Fink, G., Zhou, B., Hystad, P., et al., 2017. Elevated blood pressure and household solid fuel use in premenopausal women: analysis of 12 Demographic and Health Surveys (DHS) from 10 countries. Environ. Res. 160, 499-505.

Auchincloss, A.H., Diez Roux, A.V., Dvonch, J.T., Brown, P.L., Barr, R.G., Daviglus, M.L., et al., 2008. Associations between recent exposure to ambient fine particulate matter and blood pressure in the Multi-ethnic Study of Atherosclerosis (MESA). Environ. Health Perspect. 116 (4), 486-491.

Baumgartner, J., Schauer, J.J., Ezzati, M., Lu, L., Cheng, C., Patz, J.A., et al., 2011. Indoor air pollution and blood pressure in adult women living in rural China. Environ. Health Perspect. 119 (10), 1390-1395.

Baumgartner, J., Zhang, Y., Schauer, J.J., Huang, W., Wang, Y., Ezzati, M., 2014. Highway proximity and black carbon from cookstoves as a risk factor for higher blood pressure in rural China. Proc. Natl. Acad. Sci. U. S. A. 111 (36), 13229-13234.

Bo, Y., Guo, C., Lin, C., Chang, L.Y., Chan, T.C., Huang, B., et al., 2019. Dynamic changes in long-term exposure to ambient particulate matter and incidence of hypertension in adults. Hypertension 74 (3), 669-677.

Brook, R.D., Rajagopalan, S., Pope 3rd, C.A., Brook, J.R., Bhatnagar, A., Diez-Roux, A.V., et al., 2010. Particulate matter air pollution and cardiovascular disease: an update to the scientific statement from the American Heart Association. Circulation 121 (21), 2331-2378.
Bruce, N., Pope, D., Rehfuess, E., Balakrishnan, K., Adair-Rohani, H., Dora, C., 2015 WHO indoor air quality guidelines on household fuel combustion: strategy implications of new evidence on interventions and exposure-risk functions. Atmos. Environ. 106, 451-457.

Burnett, R.T., Pope 3rd, C.A., Ezzati, M., Olives, C., Lim, S.S., Mehta, S., et al., 2014. An integrated risk function for estimating the global burden of disease attributable to ambient fine particulate matter exposure. Environ. Health Perspect. 122 (4), 397-403.

Cabrera, S.E., Mindell, J.S., Toledo, M., Alvo, M., Ferro, C.J., 2016. Associations of blood pressure with geographical latitude, solar radiation, and ambient temperature: results from the Chilean health survey, 2009-2010. Am. J. Epidemiol. 183 (11), 1071-1073.

Cai, Y., Zhang, B., Ke, W., Feng, B., Lin, H., Xiao, J., et al., 2016. Associations of shortterm and long-term exposure to ambient air pollutants with hypertension: a systematic review and meta-analysis. Hypertension 68 (1), 62-70.

Chan, S.H., Van Hee, V.C., Bergen, S., Szpiro, A.A., DeRoo, L.A., London, S.J., et al., 2015. Long-term air pollution exposure and blood pressure in the sister study. Environ. Health Perspect. 123 (10), 951-958.

Chow, C.K., Teo, K.K., Rangarajan, S., Islam, S., Gupta, R., Avezum, A., et al., 2013. Prevalence, awareness, treatment, and control of hypertension in rural and urban communities in high-, middle-, and low-income countries. J. Am. Med. Assoc. 310 (9), 959-968.

Chuang, K.J., Yan, Y.H., Cheng, T.J., 2010. Effect of air pollution on blood pressure, blood lipids, and blood sugar: a population-based approach. J. Occup. Environ. Med./Am. Coll. Occup. Environ. Med. 52 (3), 258-262.

Chuang, K.J., Yan, Y.H., Chiu, S.Y., Cheng, T.J., 2011. Long-term air pollution exposure and risk factors for cardiovascular diseases among the elderly in Taiwan. Occup. Environ. Med. 68 (1), 64-68.

Clark, M.L., Peel, J.L., Balakrishnan, K., Breysse, P.N., Chillrud, S.N., Naeher, L.P., et al., 2013. Health and household air pollution from solid fuel use: the need for improved exposure assessment. Environ. Health Perspect. 121 (10), 1120-1128.

Collaborators, R.F., 2018. GBD 2017 Risk Factor Collaborators Global, regional, and national comparative risk assessment of 84 behavioural, environmental and occupational, and metabolic risks or clusters of risks for 195 countries and territories, 1990-2017: a systematic analysis for the Global Burden of Disease Study 2017. Lancet 392, 1923-1994.

Du, Y., Xu, X., Chu, M., Guo, Y., Wang, J., 2016. Air particulate matter and cardiovascular disease: the epidemiological, biomedical and clinical evidence. J. Thorac. Dis. 8 (1), E8-E19.

Fuks, K., Moebus, S., Hertel, S., Viehmann, A., Nonnemacher, M., Dragano, N., et al., 2011. Long-term urban particulate air pollution, traffic noise, and arterial blood pressure. Environ. Health Perspect. 119 (12), 1706-1711.

Fuks, K.B., Weinmayr, G., Hennig, F., Tzivian, L., Moebus, S., Jakobs, H., et al., 2016. Association of long-term exposure to local industry- and traffic-specific particulate matter with arterial blood pressure and incident hypertension. Int. J. Hyg Environ. Health 219 (6), 527-535.

Green, M.S., Jucha, E., Luz, Y., 1986. Blood pressure in smokers and nonsmokers: epidemiologic findings. Am. Heart J. 111 (5), 932-940.

Guenther, P.M., Reedy, J., Krebs-Smith, S.M., 2008. Development of the healthy eating index-2005. J. Am. Diet Assoc. 108 (11), 1896-1901.

Honda, T., Pun, V.C., Manjourides, J., Suh, H., 2018. Associations of long-term fine particulate matter exposure with prevalent hypertension and increased blood pressure in older Americans. Environ. Res. 164, 1-8.

Kwan, G.F., Mayosi, B.M., Mocumbi, A.O., Miranda, J.J., Ezzati, M., Jain, Y., et al., 2016 Endemic cardiovascular diseases of the poorest billion. Circulation 133 (24) $2561-2575$.

Lee, M.S., Hang, J.Q., Zhang, F.Y., Dai, H.L., Su, L., Christiani, D.C., 2012. In-home solid fuel use and cardiovascular disease: a cross-sectional analysis of the Shanghai Putuo study. Environ. Health 11, 18.

Lewington, S., Li, L., Sherliker, P., Guo, Y., Millwood, I., Bian, Z., et al., 2012. Seasonal variation in blood pressure and its relationship with outdoor temperature in 10 diverse regions of China: the China Kadoorie Biobank. J. Hypertens. 30 (7), 1383-1391.

Liang, R., Zhang, B., Zhao, X., Ruan, Y., Lian, H., Fan, Z., 2014. Effect of exposure to PM2.5 on blood pressure: a systematic review and meta-analysis. J. Hypertens. 32 (11), 2130-2140 discussion 41.

McCracken, J.P., Smith, K.R., Diaz, A., Mittleman, M.A., Schwartz, J., 2007. Chimney stove intervention to reduce long-term wood smoke exposure lowers blood pressure among Guatemalan women. Environ. Health Perspect. 115 (7), 996-1001.

McCracken, J.P., Wellenius, G.A., Bloomfield, G.S., Brook, R.D., Tolunay, H.E. Dockery, D.W., et al., 2012. Household air pollution from solid fuel use: evidence for links to CVD. Glob. Heart 7 (3), 223-234.

Modesti, P.A., 2013. Season, temperature and blood pressure: a complex interaction. Eur. J. Intern. Med. 24 (7), 604-607.

Newby, D.E., Mannucci, P.M., Tell, G.S., Baccarelli, A.A., Brook, R.D., Donaldson, K., et al., 2015. Expert position paper on air pollution and cardiovascular disease. Eur. Heart J. 36 (2), 83-93b.

Pope, C.A., Turner, M.C., Burnett, R.T., Jerrett, M., Gapstur, S.M., Diver, W.R., et al., 2015. Relationships between fine particulate air pollution, cardiometabolic disorders, and cardiovascular mortality. Circ. Res. 116 (1), 108-115.

Quinn, A.K., Ae-Ngibise, K.A., Jack, D.W., Boamah, E.A., Enuameh, Y., Mujtaba, M.N. et al., 2016. Association of Carbon Monoxide exposure with blood pressure among pregnant women in rural Ghana: evidence from GRAPHS. Int. J. Hyg Environ. Health 219 (2), 176-183. 
Ramli, A., Halmey, N., Teng, C., 2008. White coat effect and white coat hypertension: one and the same? Malays. Fam. Physician 3 (3), 158-161.

Shah, A.S., Lee, K.K., McAllister, D.A., Hunter, A., Nair, H., Whiteley, W., et al., 2015 Short term exposure to air pollution and stroke: systematic review and metaanalysis. BMJ 350, h1295.

Smith, K.R., Bruce, N., Balakrishnan, K., Adair-Rohani, H., Balmes, J., Chafe, Z., et al., 2014. Millions dead: how do we know and what does it mean? Methods used in the comparative risk assessment of household air pollution. Annu. Rev. Publ. Health 35, 185-206.

Teo, K., Chow, C.K., Vaz, M., Rangarajan, S., Yusuf, S., Group, P.I.-W., 2009. The Prospective Urban Rural Epidemiology (PURE) study: examining the impact of societal influences on chronic noncommunicable diseases in low-, middle-, and high-income countries. Am. Heart J. 158 (1), 1-7 e1.

Tzoulaki, I., Elliott, P., Kontis, V., Ezzati, M., 2016. Worldwide exposures to cardiovascular risk factors and associated health effects: current knowledge and data gaps. Circulation 133 (23), 2314-2333.

van Donkelaar, A., Martin, R.V., Brauer, M., Hsu, N.C., Kahn, R.A., Levy, R.C., et al. 2016. Global estimates of fine particulate matter using a combined geophysicalstatistical method with information from satellites, models, and monitors. Environ. Sci. Technol. 50 (7), 3762-3772.

Xie, X., Wang, Y., Yang, Y., Xu, J., Zhang, Y., Tang, W., et al., 2018. Long-term effects of ambient particulate matter (with an aerodynamic diameter $</=2.5$ mum) on hypertension and blood pressure and attributable risk among reproductive-age adults in China. J. Am. Heart Assoc. 7 (9).

Yan, Z., Liu, Y., Yin, Q., Qiu, M., 2016. Impact of household solid fuel use on blood pressure and hypertension among adults in China. Air Qual. Atmos. Health $1-10$.

Young, B.N., Clark, M.L., Rajkumar, S., Benka-Coker, M.L., Bachand, A., Brook, R.D., et al., 2019. Exposure to household air pollution from biomass cookstoves and blood pressure among women in rural Honduras: a cross-sectional study. Indoor Air 29 (1), 130-142.

Yusuf, S., Hawken, S., Ôunpuu, S., Dans, T., Avezum, A., Lanas, F., et al., 2004. Effect of potentially modifiable risk factors associated with myocardial infarction in 52 countries (the INTERHEART study): case-control study. Lancet 364 (9438), 937-952.

Yusuf, S., Rangarajan, S., Teo, K., Islam, S., Li, W., Liu, L., et al., 2014. Cardiovascular risk and events in 17 low-, middle-, and high-income countries. N. Engl. J. Med. 371 (9), 818-827.

Zhang, Z., Guo, C., Lau, A.K., Chan, T.-C., Chuang, Y.C., Lin, C., et al., 2018. Long-term exposure to fine particulate matter, blood pressure, and incident hypertension in Taiwanese adults. Environ. Health Perspect. 126 (1), 017008. 